\title{
Alguns aspectos do uso da informação na economia da informação
}

\author{
Max F. C ohen \\ D outorando em A dministração de Empresas na Escola de \\ A dministração de Empresas de São Paulo, da Fundação G etúlio \\ Vargas. M estre em A dministração pela U niversidade Federal de \\ Santa C atarina. Bacharel em Economia pela U niversidade Federal \\ do A mazonas. \\ E-mail: maxfc@gvmail.br
}

\author{
INTRO DU ÇÃ O
}

M uito se tem falado a respeito de uma nova economia, em um ambiente de rápidas tranforformações enovostipos denegócios. A principal característicaseriaa quantidade deinformações aserem processadas por uma organização, que cresceu muito quando comparadaao montanteque se processava háalguns anos. 0 advento daI nternet ea possibilidade de realizar negócios de formas diversas fizeram surgir uma preocupação quanto ao processamento de informações necessárias à tomada de decisões no ambiente denegócios daempresa.

Então, pergunta-se: "São necessárias novas regras paraa economia?" Shapiro \& Varian ${ }^{1}$ afirmam que as mudanças vistas hojesão decorrentes dos avanços tecnológicos, mas as leis da economia continuam valendo. $\mathrm{N}$ ão mudaram. A mudançana economia estána forma em que se usaa informação, daí o termo, mais apropriado, deeconomia da informação.

Segundo Evans \& Wurster ${ }^{2}$, amudançafundamental com a economiadainformação não éespecificamentealguma tecnologia, mas o novo comportamento dos agentes econômicos, que surgiu e está al cançando uma massa crítica. O s autores vislumbram o surgimento da conectividade entre as pessoas. Tal movimento tem causado transformações profundas na forma de as organizações operarem enanecessidadedese repensarem os fundamentos da estratégia empresarial.

Essas transformações podem ser entendidas como as novas formas de negócios, comunicação e interação. $\mathrm{N}$ ovas tecnologias a cada dia possibilitam melhorias que diminuem obstáculos como tempo e espaço. Tanto as pessoas quanto as organizações têm trocado mais informações, seja pelo envio de mensagens ou troca de arquivos. 0 surgimento da conectividade criauma série de benefícios jamais imaginados. $\mathrm{H}$ áalgum tempo, as pessoas têm trocado música por meio de fitas cassetes, discos de vinil e CD. A té então a troca (ou às vezes empréstimos) demúsicaestácondicionadaa uma troca de bens físicos. Q uem poderia prever que um dia as pessoas estariam trocando música entre si de maneira digital, on-line, sem qualquer contato físico? O N apster 


\section{Alguns aspectos do uso da informação na economia da informação}

entendeu o que seria conectividade e proporcionou às pessoas algo real mentenovo.

$\mathrm{N}$ esses termos, a conectividade seria uma oportunidade criada pela tecnologia ${ }^{2}$. A tecnologia por sua vez seria o instrumento que criou tal ambiente. Resta agora entender o fluido queirriga esse ambiente, fazendo com que a tecnologia funcione e a conectividade exista - a informação.

Esteartigo é parte da revisão de literatura do projeto da tese dedoutorado em andamento, a qual tem como objetivo principal desenvolver e testar um modelo conceitual de medição do uso da informação pelaaltagerência das organizações. A téo momento foram identificadas potenciais dimensões deanálise. Estas dimensões passarão a ser os constructos a serem testados, buscando-se, por meio daA nálise F atorial Confirmatória, na próxima fase da pesquisa, suas confirmações ea estruturação da escala para medição.

\section{A IN FO RMAÇÃO}

O estudo da informação está no âmbito da Teoria da Informação. Esta teoria foi formalizada no início do século XX, alicerçadaem um sistemadebasematemática, cujo objetivo era estudar os problemas detransmissão de mensagens. Preocupava-se naquele momento com a quantidade de informação suportável por um dado canal, em busca de prever ecorrigir as distorções que pudessem ocorrer durante a transmissão. A ssim, tal teoria era apresentada como uma técnica da engenharia de comunicações vindo a ser denominada Teoria $M$ atemática dal nformação, ou ainda Teoria M atemática daC omunicação³.

Para a análise informacional, a informação é um agente dissipador de incertezas cujo objetivo é proporcionar alterações no comportamento das pessoas, reduzindo a incerteza ${ }^{4}$. D iferencia-se da informática e da cibernética. A informáticatem o objetivo de tratar da automação da informação, ea cibernética volta-se para os problemas de controle da informação nas máquinas e nos organismos vivos 5 .

A mudançano comportamento do receptor de uma dada mensagem dependedo quanto de novo tem a mensagem. A ssim, entende-se que, quanto maior for a taxa de novidade, maior seráa mudança no comportamento das pessoas. I sso leva ao estabelecimento dainteração entre taxa de informação e originalidade: mais informação resulta de maior originalidade, ou menor previsibilidade.
A buscapelo novo ésempreum desafio. Entretanto, não hájustificativa parauma incessante busca do novo atodo custo. Isto traria a negação do que foi adquirido no passado. R essalta-se ainda que a valorização do que é novo é fomentada pela sociedade, podendo ser desestimulada em um momento efomentada em outro ${ }^{5}$.

Então verifica-se queaquestão daoriginalidadeéquedá valor ainformação. $N$ ão pode ser em excesso, nem nula. A mensagem de maior valor é aquela que tende para a entropiamáxima, sem nelacair. A mensagem ideal pode ser caracterizada co mo aquela que possui o máximo de informação, ou com tendência a entro pia ${ }^{3}$. C ontudo, à medida que a taxa de informação aumenta em uma mensagem, menor será sua inteligibilidade (e o inverso também é verdadeiro). U sa-se nessa ocasião o efeito da redundância, que é a forma de tornar mais clara a mensagem, de modo a absorver os possíveis ruídos que nela existam. Como ruído entende-setodo sinal ou signo inserido na mensagem que não se pretendia transmitir, prejudicando sua intelecção ${ }^{5}$. Falhas observadas na transmissão de uma informação podem surgir, uma vez que o emissor, normalmente o subordinado em uma organização, não compreende a(s) necessidade(s) do receptor, ou seja, do chefe $e^{6}$.

$\mathrm{N}$ este artigo, entende-se por informação:

“(...) qualquer coisa que possa ser digitalizada, transformada em um fluxo de bits" ${ }^{1}$; sendo dados estruturados cujaforma e conteúdo são apropriados para um uso em particular, possuindo significado contextual, de utilidade, proporcionando incremento ao conhecimento estabelecido $0^{5,7,8,9,10}$.

A contextualização é a principal característica para a informação. U ma informação pode ser importante, ter valor, fazer sentido para uma pessoa, e não causar nenhuma mudança em outrapessoa. A informação, por fim, representaal go que existe. "A informação, numérica ou não, não é uma abstração, mas está inexoravelmente ligada a uma representação física (...) A ssim, o processamento da informação está inexoravelmente ligado ao universo material esuas leis" ${ }^{\prime 1}$.

$\mathrm{H}$ oje o mundo passa pelo problema de se ter muitas informações, significando uma sobrecarga. D eve-se tomar cuidado com o excesso. C omo disseH erbert Simon, citado por Shapiro \& Varian", "ariqueza dainformação cria a pobreza da atenção". Essa sobrecarga édecorrente de avanços tecnológicos que têm proporcionado um crescente aumento no número de dispositivos quetratam 
a informação. M as não é esse o ponto mais relevante de estudo atualmente. A maior preocupação daciência deve estar em entender como ainformação étransmitida, como podeser armazenada ecomo pode ser usada para tomar decisões ${ }^{6}$.

D avenport ${ }^{12}$ estruturaagestão da informação em quatro etapas: a) determinação de exigências; b) obtenção; c) distribuição; d) utilização. A firmaainda que " (...) o uso da informação é algo bastante pessoal" e que é "(...) relativamentefácil estimar esse uso". 0 u seja, agestão da informação preocupa-se com o indivíduo, o que este precisae como utiliza.

\section{COMO ASEMPRESASUTILIZAM A IN FO RMAÇÃO}

Se as regras da economia não mudaram e a sociedade encontra-sehoje inserida em uma economia baseada na informação, como as empresas estão usando ainformação paracompetir no mercado? A preocupação com o uso da informação nos negócios éum assunto queestána pauta da academia há algum tempo. A credita-se que a organização baseada na informação é o modelo de organização do futuro, fundamentadano conhecimento eformada por especialistas ${ }^{13}$.

Porter \& M illar ${ }^{14}$ afirmam que as transformações nas organizações eram oriundas da "revolução da informação". Segundo eles, observam-se reduções de custos, deprocessamento etransmissão de informações, e estes fatos trazem novas formas aos negócios. F azem um al ertaaos gerentes: “É necessário o uso adequado das informações para que as organizações consigam vantagens competitivas."

A sociedadeentrana década de 1990, e o termo revolução da informação continua na pauta do dia das instituições. $M$ as pouco se entendia no início sobre as causas, os usos e as conseqüências da informação nos negócios. $M$ ais para o fim da década, as teorias a respeito do tema começam aser mais bem discutidas, buscando-se explicar as mudanças que aconteciam e que estavam para acontecer.

A tualmente ainformação éutilizada de diversas formas. U sa-se a informação parasaber como agem os clientes, para controlar estoques, aumentar a produtividadeetc. A informação pode ser um ativo, ou simplesmenteuma ferramentadesuporteàdecisão. Em diversas publicações, a informação étratadacom finalidades comuns, masnem sempre explícitas.

\section{R edução de custos}

A buscapelaredução de custos éa proposição inicial do uso da Tecnologia da I nformação (TI ) 10,15. Por meio da reestruturação das funções organizacionais e introdução de eficientes sistemas transacionais, tem-se buscado a diminuição do tráfego de papel nos escritórios e a automação de diversas atividades básicas. $\mathrm{N}$ o modelo de análise da informatização da empresa, percebe-se quea redução de custo écaracterística do primeiro estágio de evolução da informática na organização - o estágio de iniciação $0^{16}$.

Com o tratamento automático da informação, a organização écapaz de adquirir economia de escala, que Ihetrará por conseguintea redução decusto deoperação. O s sistemas transacionais são os maio res responsáveis pela redução de custos ${ }^{9,17}$. São sistemas para automação de escritório, automação comercial e automação industrial, empregados na contabilidade, folha de pagamento, contas a pagar, contas a receber, controle físico de estoqueetc.

Segundo A Iter 7 , o custo é o principal determinante da satisfação do cliente. Com o uso de Sistemas de I nformações (SI ), busca-se reduzir custos tanto para clientes internos como externos, e as medidas típicas paracustos são o preço deaquisição, custo depropriedade emontante de tempo, além da atenção requerida.

Percebe-sequea informação écapaz de alterar os custos em qual quer parte da cadeia de val or deum firma ${ }^{14}$. N 0 passado, a ênfaseera dada na redução de custos mediante processamento repetitivo da informação, como no exemplo da digitação. A tualmente, atémesmo umalinha fabril écapaz de reduzir custo, umavez quea produção processe informações necessárias para controle de estoque de matérias- primas, hora/máquina disponível etc.

Como exemplo prático do impacto do uso da informação para redução de custo, tem-se o caso da G O L L inhas A éreas, que entrou no mercado de aviação brasileiro utilizando um avançado sistema de informação para manutenção das aeronaves e outro para vendade bilhetes por telefonee pela I nternet ${ }^{18}$. $\mathrm{N}$ o pátio do aeroporto, 0 SI avalia diariamente a situação mecânica e operacional de cada aeronave, o que proporciona 12 meses de vôos durante 0 ano, enquanto a concorrência coloca o seu avião no ar durante 11 meses. $N$ a verdade, a informação gerenciada permite saber diariamente a condição de manutenção operacional da aeronave, de forma que 


\section{A Iguns aspectos do uso da informação na economia da informação}

eliminaum mês queo aparel ho teria deficar detido para reparo. A venda de bilheteson-line, por suavez, permite à $\mathrm{G} O \mathrm{~L}$ não manter custos fixos com agências físicase disponibiliza a qualquer momento, para qualquer funcionário, a quantidade de passageiros em uma aeronave, possibilitando adequação de combustível e alimentação a serem gastos.

Para H owell ${ }^{19}$, as iniciativas de redução de custos têm sido praticadas deseteformas:

a) Análisedecusto elucratividade- visando a entender os direcionadores de custos ea identificar os produtos mais lucrativos, utilizando, por exemplo, custeio A BC.

b) Eliminação dedesperdício efoco em operações- sabidos quais os custos e os diferentes clientes, eliminam-se os produtos e clientes de baixalucratividade, em busca de diminuir os custos no geral.

c) O rganizaçõesfocadasehorizontais- orientadas mais para as necessidades e expectativas dos clientes do que em previsões e expectativas internas, resultando no alinhamento e velocidade dos processos para geração de satisfação dos clientes.

d) Planejamento do custo do produto ( target costing) - baseado no preço em que os clientes estão dispostos a pagar pelo produto/serviço.

e) G erenciamento da cadeia desuprimentos, análiseda cadeia devalor eoutsourcing- significa entender como oscustos são originados e as prováveis formas de diminuição.

f) Kainzen costing - ou aprimoramento do custeio, significa estar atento continuamente para oportunidades que tragam cortes de custos do negócio, o queépossível ter dentro deuma cultura organizacional própria.

g) E conomia de ativos - investir somente nos ativos necessários ao desenvolvimento do negócio, buscando minimizar o desperdício.

$\mathrm{N}$ o tocanteà cadeia de suprimentos deumafirma, $\mathrm{Fine}^{20}$ sugere que esta devaser encarada como um conjunto de cadeias de capacidades. $\mathrm{N}$ a gestão da cadeia, a montante (do lado dos fornecedores) e a jusante (do lado dos clientes), a firma deve buscar adquirir velocidade para a sua cadeia, deformaaconquistar reduções decustos. U m dos benefícios da gestão da cadeia de suprimentos é a redução de estoques. A lém disso, a capacidade gerada por essa cadeia permite a especialização de atividades, para cada organização quefaz parte da cadeia, de modo a trazer redução nas operações, sejaem tempo ou em custo. Tudo isso tendo como basea infra-estrutura de TI eum rico fluxo de informação.

O fluido que movimenta essa cadeia éa informação. N o ajuste ideal do tráfego de informação entrea empresae os fornecedores, ter-se-á um fornecimento de insumos adequado em tempo eem custo. Com ainformação básica do lado do cliente, a empresa poderá competir, tendo a noção das necessidades e preferências dos consumidores dos seus produtos, possibilitando a entrega em tempo e com características exigidas (ou esperadas).

Como exemplo de redução de custo na cadeia de suprimentos, tem-se o uso do Electronic D ata Interchange(EDI) naconexão entreempresa-fornecedor, com o intuito de reduzir custos com estoque, otimizar a expedição no tempo gasto com pedidos e no tamanho dos lotes remetidos ${ }^{21}$. 0 utro exemplo éo das aplicações para manutenção e reparo $M$ aintenance, $R$ epair and $O$ verhaul (M RO ). 0 uso daTI nesse campo permiteàs empresas aéreas ganho em eficiência, captura do conhecimento e redução de custo. A s fornecedoras de serviços para as empresas aéreas passam a ter melhores informações sobre as necessidades do setor, incluindo planejamento, status dos reparos e modificações a serem feitas ${ }^{22}$. Tudo isso influi para a diminuição dos custos de operação.

$\mathrm{N}$ aformação do target costing, Shapiro \& Varian ${ }^{1}$ lembram que, na economia da informação, os bens informacionais possuem um custo al to de produção, mas são baratos para reprodução. E m outras palavras, éafirmar que “(...) um bem da informação envolvealtos custosfixos, mas baixos custos marginais". I sso implica "(...) fixar o custo da informação deacordo com seu valor, não com o seu custo". A redução de custo pelo uso estratégico da informação acarreta ganho para a competitividade da organização e contribui indiretamente para agregação de valor para o produto e/ ou para a própria cadeia de valor da firma.

\section{C riação devalor}

Para os pesquisadores da área de economia industrial, valor éo quanto os consumidores estão dispostosa pagar a mais por um produto ou serviço ${ }^{23}$. U m negócio tornase lucrativo à medida que o valor criado ultrapassa os seus custos. E o uso intensivo daTI possibilitaa ampliação desseganho.

Segundo Porter \& Millar ${ }^{14}$, cada atividade de valor, dentro dacadeia de val or, utilizacomponentes físicose informacionais. A TI seencarrega de capturar, manipular 


\section{Max F. Cohen}

e distribuir a informação necessária a cada atividade. A criação de valor pela TI está direcionadaà eficiência que esta promove aos processos dispostos na cadeia de valor. I sso significa indagar, no caso daatividadedeloǵstica de saída, o quanto mais rápida pode ser a entrega do produto ao clientecom o uso daTI ? C abeàgerênciafazer estequestionamento deforma aentender como aTI traria benefícios, ou, em outras palavras, criaria valor.

Para R amirez ${ }^{24}$, as idéias de val or originárias da indústria são limitadas. Existe uma alternativa que vai além da cadeia de valor - aco-produção do valor. Enquanto paraa economia industrial o valor é criado de maneira seqüencial, dentro de uma cadeia de valor, percebendose a agregação ( ou adição) ea destruição do valor pelo consumidor, na co-produção de valor esta considera a criação de valor de forma não-linear, interativa, com vários autores no processo de produção, e de maneira transitiva. A lém disso, os consumidores, nestaótica, não destroem o valor.

0 que Ramirez ${ }^{24}$ desenvolveu éumframework quedáuma nova visão a respeito da criação do valor. Sobretudo, destacam-se a interação entre os atores econômicos, a interconectividadee asincronização das ações. Essa idéia écorroborada por Stabell \& F jeldstad ${ }^{25}$, quando afirmam quea lógica de criação de valor em uma redeépor meio do linkingentre os clientes.

A credita-se, portanto, que o valor é exógeno à firma, caracterizado pelo poder de relacionamento de clientee de fornecedores ${ }^{26,27}$. I sso implica novas práticas para definição de negócios, estruturação da organização, gerência e para a busca de produtividade na economia atual. Para Venkatraman ${ }^{28}$, a TI pode colaborar intensivamente para obtenção dessas mudanças. Entretanto, a TI podealavancar a performance daempresa, mas so mente ocorrerá se acompan hada pela gestão de informações ${ }^{12,29}$.

Sawhney ${ }^{30}$ atribui a tal sincronização uma forma de obtenção de mel hores resultados para o negócio. I sso significa utilizar a informação de formasincronizadano negócio. A s organizações devem separar os recursos focados no produto para uma estratégia de recursos focados no cliente, mas sem precisar derrubar as paredes das empresas, ou mesmo unir apressadamente unidades de negócios. A resposta está em unificar as informações sobre os clientes, dispersas na empresa, e utilizálas de formaa maximizar sua utilidadee aplicação.
A Palm (www.palm.com) foi inovadora quando disponibilizou no mercado um palmtop capaz de sincronizar dados com o computador de mesa. I sso agregou um val or sem comparação com os concorrentes, que passaram a copiar a idéia. D a mesma forma nos negócios, a sincronização deinformações, seja declientes, fornecedores, estoques, manutenção etc., criavalor para o negócio ${ }^{31}$.

Litan \& Rivlin ${ }^{32}$, em um estudo sobre o impacto da Internet na economia, concluem que essa tecnologia proporciona benefícios muito mais direcionados a melhorar a conveniência e escolha do consumidor do que aumentar a produtividade ediminuir preços. 0 u seja, al nternet tem estado presentenavida das pessoas como um mecanismo que, no fim, transmite informações. É uma verdadeira arma nas mãos dos consumidores, fazendo com queosmesmos estejam mais bem informados sobre o que desejam, quais as opções disponíveis paraa escolha, diminuição daburocracia, entre outras ${ }^{31}$.

Para H orovitz ${ }^{33}$, é necessário ir além da satisfação. É preciso criar um vínculo entre o cliente ea empresa. Para seter esse vínculo, cabeà empresa: a) conquistar o cliente, b) tornar o cliente satisfeito e, então; c) desenvolver a lealdade. Para conquistar, são precisos dois tipos de informações: a) informações para targeting identificando quais são os clientes; b) informações para customização - deformaaadaptar o produto/ serviço de acordo com as necessidades dos clientes.

Parasatisfação, o ideal éconseguir exceder as expectativas iniciais do cliente. É necessáriaa captura de quatro tipos deinformações: a) informações necessárias à adaptação do serviço de entrega às especificações de cada cliente; b) informações de feedback provenientes de clientes insatisfeitos; c) informações específicas de como encantar cada cliente; d) informações queverifiquem se o serviço de entrega corresponde aos padrões requisitados (exemplo: indicadores dequalidade).

A lealdade constitui o terceiro patamar. É aleal dade que garante uma nova compra, o que requer um constante reforço da satisfação gerada anteriormente. Em um planejamento para garantir a lealdade da clientela, é necessário um SI queforneça detal hes de cada cliente, incluindo: a) comportamento decompra (o que, quando, quanto, ondeepor quê); b) preferências de comunicação (correio, correio eletrônico, fax, tel efone, visitas); c) atualização constante sobre o consumidor; d) custo/ benefício (global epara cada cliente). 


\section{Alguns aspectos do uso da informação na economia da informação}

N esse momento, o comprometimento da organização com a leal dade a ser estabelecida será praticada com o uso desistemas como o data warehousee O LAP ( 0 n-Line Analytical P rocessing), em virtude daquantidade de dados aserem manipulados e aforma como devem ser tratados. A utilização de tais tipos de sistemas começa pela limitação dos tradicionais EIS (Executive I nformation Systems). A ssim, tais sistemas constituem soluções flexíveis orientadas para problemas gerenciais do tipo proposto ${ }^{34,35}$.

\section{A interconectividade, as redesea criação devalor}

A criação de valor a partir da interconectividade, comentada anteriormente, está diretamente ligada à capacidade de formação de redes. A s redes têm sido utilizadas para transportar pessoas, bens e informações entre dois pontos distintos, ou mais. Esses tipos de redes constituem os negócios baseados em rede( network-based businesses), que podem ser exemplificados como as operadoras de telecomunicações, as companhias de transporte, as instituições financeiras e até mesmo as organizações quelidam com saúde ${ }^{36}$.

ParaSawhney \& Parik ${ }^{37}$, aredeéaeconomia. U marede éum meio de condução de informações, não importaa sua complexidade. A inteligência de uma rede está em sua funcionalidade, que é a maneira de distribuir, armazenar, criar ou modificar informações. A I nternet é uma rede digital do tipo smart, capaz deampliar autilidade das informações de diversas maneiras. E isso significa criar valor.

A criação devalor em rede se dáa partir da conexão das várias atividadegeradoras de valor, formando um sistema de atividades que possam caracterizar o negócio como único e tornar difícil sua replicação. A vantagem competitiva está em conectar, e não simplesmente colecionar atividades quesustentem valor ${ }^{38}$.

Para se criar valor em uma rede, não importando qual seja, é necessário o entendimento sobre dois componentes da inteligência: o back-end e o front-end. A s redes modernas empurram as inteligências back-end e front-end em sentidos opostos. A inteligênciaback-end diz-seser a infra-estrutura compartilhada pelo principal propósito da rede, enquanto a inteligênciafront-end é fragmentada de diversas maneiras na periferia da rede, ondeestão os usuários ${ }^{37}$. D essaforma, umaorganização é capaz de mobilizar partes da inteligência que estão na rede, como moléculas.
O projeto SETI @ home(http:// setiathome.ssl.berkeley. edu), daU niversidade daC al ifórnia, tem como objetivo o estudo de vida extraterrestre e mo biliza unidades de trabal ho em rede. Em abril de 2002, participavam 226 países, mais de 3,6 milhões de pessoas. 0 back-end do projeto distribui trabalho para microcomputadores conectados àl nternet, deformaater um processamento paral elo. Resultado: o valor gerado foi determinado pela possibilidade de se prover algo como $280 \mathrm{mil}$ anos de tempo destinado ao processamento, com o poder de 12 teraflops, tornando-se quatro vezes mais rápido do que um supercomputador.

A utilização da mobilização de competências traz profundas mudanças organizacionais. Conectadas em redes, diferentes organizações podem facilmente combinar suas capacidades e recursos para uma aliança temporária e flexível com o objetivo de explorar oportunidades demercado.

F ine ${ }^{20}$ afirma que éimprescindível, para a obtenção do sucesso, compreender a complexidadee a dinâmica das forças atuantes no setor e elaborar mapas da cadeia de fornecimento daempresa. I sso significater um mapa que possibilite olhar as três dimensões da cadeia de fornecimento: as empresas, as tecnologias e a rede de capacidades. U m mapa é o início do processo de reformulação dacadeia de capacidades deuma empresa, no qual se identifica o seguinte: (a) as organizações envolvidas nas atividades da empresa; (b) os subsistemas fornecidos por estas empresas; (c) as capacidades queelas trazem para a proposição de val or; (d) as contribuições tecnológicas decadauma parao produto final da empresa.

\section{Inovação}

A economia da informação requer organizações que estejam engajadas na constante busca da inovação. Perfis inovadores e dinâmicos são requisitos para 0 planejamento das operações nal nternet ${ }^{39}$. Por suavez, os sistemas de informações precisam ser flexíveis de modo quesuportem modificações deprodutos, de processose daprópriaorganização ${ }^{10}$.

O uso da informação proporciona novos tipos de produtos eserviços, o quelevaà customização em massa enovos tipos de negócios ${ }^{7}$. N ovos negócios podem ser caracterizados pela transformação de um negócio já existente mediante uso intensivo da informação, como no caso daF edEx, ou na criação de um outro negócio, como o exemplo das firmas prestadoras de serviço de conexão por bandalarga14. 


\section{Max F. Cohen}

U m exemplo bastante debatido éo caso das livrarias na Internet. Barnes \& N oble (www.b\&n.com) e A mazon.com (www.amazon.com) seestabelecem com um novo conceito denegócio para vender livros. D entresuas várias características, destacam-se por conectarem-se com clientes de locais remotos, buscaem um catálogo de milhares detítulos, customização no oferecimento de lançamentos.

$\mathrm{N}$ a Economia da Informação as empresas estão experimentando inovar com a melhor interação entre os seus departamentos de desenvolvimento de produtos. Por meio desoftwares, as áreas dedesign de produtosede engenharia "conversam" deforma mais produtiva. Buscase a melhoria do tráfego de informação permitindo a otimização do fluxo de informação ea redução do tempo de desenvolvimento de um projeto. A inovação tradicional baseada na tentativa e erro promove muitos desperdícios. C om o uso dainformação, esse desperdício éminimizado ${ }^{40}$.

A interação buscando inovação também acontece no relacionamento entrea empresa eo cliente. A s empresas estão fornecendo aos seus clientes ferramentas que, usando al nternet, proporcionam a seleção emanipulação de informações dedesign edesenvolvimento dos produtos. Em outras palavras, as empresas estão permitindo queos clientes criem os produtos. Esta ação melhora asatisfação do cliente, quemuitas vezes não éatendido simplesmente porquea pesquisa demarketingnão foi capaz deidentificar suas necessidades. A empresafornece a ferramenta, eo cliente então torna-se co-responsável na inovação de produtos. Em fim, têm-se produtos mais próximos da necessidade dos clientes eem menos tempo ${ }^{41,42}$.

A informação proporcionaainovação também por meio da aprendizagem. A exploração da aprendizagem na organização não é um luxo, mas uma necessidade. $\mathrm{N}$ ecessidade esta que faz com que 0 ato de aprender configure-secomo umamaneiradeas firmas descobrirem o seu futuro. 0 fluxo de informação torna-se, então, essencial ao processo de aprendizagem ${ }^{43}$.

Aliada à aprendizagem, tem-se a inteligência competitiva, quevisaa antecipar mudanças no ambiente competitivo ${ }^{44}$. As oportunidades de negócio estão baseadas na validação e refino de idéias e projetos a partir do constante monitoramento do ambiente em que a organização estáinserida. Entretanto, só háinteligência quando fatos, dados e tendências são enriquecidos e interpretados. Para isso, a TI oferece ferramentas para busca, monitoramento, observação e previsão ${ }^{45}$. M ais especificamente, refere-se à gerência de conteúdo, possibilitando o acesso e o compartilhamento do conhecimento, independentementede tempo eespaço ${ }^{46}$.

“A ssim, énecessário considerar que uma empresa não inova sozinha, pois as fontes de informações, conhecimentos e inovação podem se localizar tanto dentro, como fora dela. 0 processo de inovação é, portanto, um processo interativo, realizado com a contribuição de variados agentes econômicos e sociais que possuem diferentes tipos de informações e conhecimentos" ${ }^{\prime \prime 7}$.

\section{R edução do risco}

0 risco é parte inerente do negócio, ecada gestor deve determinar o risco ao qual estará propenso, tendo em vista taxas de retorno e de crescimento. $Q$ uando da execução de mudanças, a organização torna-se alvo de riscos em potenciais. N esse caso, saindo de uma posição estável epassando a ef etuar mudanças, uma organização podeter quatro fontes geradoras derisco ${ }^{48}$ : a) mudanças naTI - novo hardware, novo softwareereconfiguração de sistemas; b) mudanças organizacionais - nova estrutura gerencial, novas diretrizes, fusão; c) mudança em processos - novos produtos, novo mercado, aquisições; d) mudanças depessoal - perdadeexecutivos importantes, nova equipe, novo presidente. $C$ abe então à direção ter um controleefetivo dessas fontes, eainformação passaa ser um elemento de controle.

A exemplo de melhor controlecom o uso da informação, no ano de 2002 o Brasil passou pela mudança do seu sistema de pagamentos. M udança esta que visa a trazer mais "segurança e confiabilidade (...)" de forma que, através de sistemason-lineseja possível a“(...) redução do risco de crédito nos pagamentos, que são irreversíveis (não podem ser sustadosou devolvidospor faltadefundos, como podeocorrer com cheques)" ${ }^{\prime 4}$.

A lém de controle da informação, pode ser usada para análi ise do risco, seja no âmbito estratégico, financeiro, operacional, comercial, técnico e/ ou ambiental. Paraisso, cabeo uso desistemas deinformações quedisponibilizem informações de maneira acurada e atual, antecipando eventuaisfatos que proporcionem risco àorganização ${ }^{50,51}$.

Com o avanço datecnologiae o surgimento dal nternet, as organizações estão sob alvo de novas vulnerabilidades. O sriscosnos sistemas deinformações podeser originários de invasões feitas por hackers, infecções por vírus, desastres (incêndios, falta de energia, roubo) e 


\section{A Iguns aspectos do uso da informação na economia da informação}

sabotagem ${ }^{9}$. Para minimização dos riscos, cabe: a) 0 controle do desenvolvimento dos sistemas; b) treinamento dos usuários sobre segurança; $c$ ) segurança física; d) controle no acesso de dados, computadorese redes; e) controle dos processos de transação; f) incentivos à eficiência e efetividade operacional; $g$ ) auditoria dos sistemas; $h$ ) plano no caso de desastre ${ }^{7}$.

Cabe, portanto, determinar quais informações os executivos precisam para tomar decisões, tendo em consideração os fatores críticos de sucesso pertinenteao negócio ${ }^{52}$.

\section{Virtualização}

Para Evans \& Wurster², a Economia da I nformação desestrutura a cadeia física de valor. Por sua vez, a informação poderecriar a cadeia devalor deacordo com o negócio estabelecido tomando uma nova forma - a virtual. A virtualização é uma condição que transcende o aspecto físico da organização.

Como uma rede, a I nternet tem proporcionado novo ambienteeconômico para as organizações. I sso significa novos canais de comunicação e detroca entre os agentes econômicos. N esseambiente, a informação torna-seum material vital para sobrevivência. Para caracterizar tal situação, o modelo ICDT (I nformation, C ommunication, $D$ istribution and Trasaction) $)^{53}$ estrutura as quatro estratégias que as empresas têm usado para competir na Internet: a) Espaço del nformação Virtual; b) Espaço de C omunicação Virtual; c) Espaço deD istribuição Virtual; d) Espaço de Transação V irtual.

A possibilidadedevirtualizar produtoseserviços, ou seja, transformar matéria em bits, éuma capacidade adquirida de al gumas organizações nos últimos anos, que, através daTI, buscam se diferenciar no mercado etransferir para o consumidor o poder de escolha. Em outras palavras, isso significadotar produtos/serviços como sendo do tipo anywhere (capaz deser usado/ acessado dequal quer lugar), anytime (capaz deser usado/ acessado a qualquer tempo) e nomatter (não éfeito de matéria, mas sim debits) ${ }^{20,54}$.

A ssim, tem-se a indicação que a informação é um elemento importantena real ização de $\mathrm{N}$ egócios naEra Digital (NED). E esses negócios pertencem a uma tendência emergenteque possui um grande potencial de inovação na economia ${ }^{31,55}$.
Para Rayport \& Sviokla 56 , o modelo dacadeia de valor tradicional trata a informação como um elemento de suporte. $\mathrm{N}$ a verdade, a informação fará diferença quando a gerência visualizar o novo ambiente em queopera - 0 marketspace. $\mathrm{N}$ esse ambiente digital, as diferenças são percebidas por a) conteúdo; b) contexto; c) infraestrutura.

$\mathrm{N}$ o ambiente digital, a empresa precisa observar outro tipo de cadeia de valor - a cadeia de valor virtual. As empresas passam a competir em dois mundos: o físico eo virtual. N aformafísica, a informação serve para controlar a cadeia, seja nos estoques, logística ou processo. N o virtual, a informação éusada para oferecer um novo tipo de valor para o cliente. A criação de valor na cadeia de valor virtual envolve cinco etapas seqüenciais: coleta, organização, seleção, sínteseedistribuição dainformação. O bservou-se que as empresas adotam a criação de valor virtual em três estágios: a) visibilidade - quando os gerentes utilizam a informação para coordenação e controle das atividades da cadeia de valor física; b) capacidade de semelhança - substituição de etapas da cadeia física para a cadeia virtual; c) novos relacionamentos com clientes - novas formas de proporcionar valor ao cliente ${ }^{57}$.

Para estar inserida na economia da informação, é necessário que a organização esteja baseada em um modelo de negócio adequado. Segundo Venkatraman \& $\mathrm{H}$ enderson ${ }^{58}$, em tempos de alta turbulência e transformações rápidas, a estratégia de se ter uma organização virtual éa mais adequada. Para virtualização de uma organização, énecessário observar:

a) Interação com o cliente - nova oportunidade no relacionamento empresa-cliente (B2C - Business To Consumer), na qual o cliente pode remotamente experimentar produtos eserviços.

b) C onfiguração do ativo - de forma que a organização passea se deter apenas no que diz respeito à suacompetência central, maximizando eflexibilizando seu relacionamento com fornecedores esubcontratados.

c) C onhecimento - como o ativo básico da organização (em detrimento a terra, máquinas ecapital), deforma que possam ser organizadas desde unidades de especialistas, no estágio 1, até a formação de uma comunidade deespecialistas.

Virtualizar significa ter uma nova forma de operar. Significa também ter uma nova concepção de cadeia de suprimentos- uma cadeia de suprimentos virtual ${ }^{59}$. U ma 
integração virtual significa ganho em velocidade, agilidade efoco em competências. São as seguintes as características que determinam a virtualização: a) velocidade - onde os negócios são processados em minutos ou horas, em vez de semanas ou meses; b) estratégi a - focada em competências ena criação de links com fornecedores, subcontratados e parceiros, objetivando fortalecer o modelo de negócio com as competências de organismos externos; c) customizaçãoatravés do relacionamento com clientes pelaWeb e com a cadeia de valor estabelecida; d) arquitetura de TI componentizada - onde diversos aplicativos se interrelacionam buscando ligar clientes, fornecedores, parceiros e funções internas, de forma a otimizar a capacidade de sistemas, trabal har a capacidade robusta dearmazenamento eintegrar as infra-estruturas físicase digitais; e) equipes - providas de ferramentas e sistemas de comunicações, garantidas por uma cultura distinta, que promove respostas rápidas, qualidade empresarial e foco no cliente.

\section{D iferenciação de produto}

A diferenciação de produto ou serviço por meio da informação é uma estratégia que visa a conquistar vantagem competitiva ${ }^{14}$. N ovos produtos têm sido ofertados com diferentes conteúdos informacionais. N 0 caso dos televisores, os menus de comandos são disponibilizados natela eo telespectador escolheem qual língua prefereler. O DVD apresenta, além das opções de diferentes línguas para o áudio ea legenda de um filme, a possibilidade denavegar pelamídiautilizando o contador (de horas, minutos e segundos). É o consumidor desfrutando a liberdade de escolha e ampliação da sua satisfação.

A informação também diferencia as tintas vendidas no varejo. 0 cliente, que sempre escolheu a cor datintaa partir de um conjunto definido, hojepodeescolher dentre infinitas combinações possíveis. C om um maquinário instalado na loja, basta o cliente informar qual a cor é desejada, e a tecnologia se encarrega de fazer as combinações necessárias. 0 produto écustomizado enão necessita de produção em escala.

O ssistemas operacionais dos computadores pessoais são diferenciados pelas informações quecarregam. É adisputa entreo W indows eo $\mathrm{M}$ acO Snaquestão dequem émelhor. $\mathrm{O}$ u no caso dos celulares, em que cada um é capaz de executar funções próprias, desdeamais simples buscana agenda interna de tel efones atéa transferência de dados vialnternet.
Provavelmente são os bancos que melhor utilizam a informação na transformação do seu próprio negócio ${ }^{60}$. $\mathrm{N}$ o passado esse segmento tinhaum conjunto de ofertas limitadas. A tualmente o leque de serviço é bastante vasto. $\mathrm{N}$ a busca pela atração e satisfação de clientes, os bancos reúnem no mundo virtual grande partedos seus serviço, identificando e classificando as necessidades individuais. $\mathrm{N}$ a Web o cliente pode encontrar, por exemplo, a proposta perfeita de um seguro residencial apropriado à sua renda, de acordo com o seu bairro eàs suas preferências ${ }^{61}$. É a informação diferenciando e customizando produtos eserviços.

\section{CONCLUSÃO}

N esteartigo buscou-sedesenvolver, com basenas teorias existentes, o referencial que estrutura o uso da informação por partedas organizações. D emodo genérico, entende-se que tal uso, visando a alcançar melhor posicionamento competitivo no mercado, édirecionado para seis estratégias genéricas (figura 1): redução de custos, criação de valor, inovação, redução do risco, virtualização ediferenciação de produto.

\section{FIGURA 1}

\section{R eferencial do uso da informação nas estratégias das organizações}

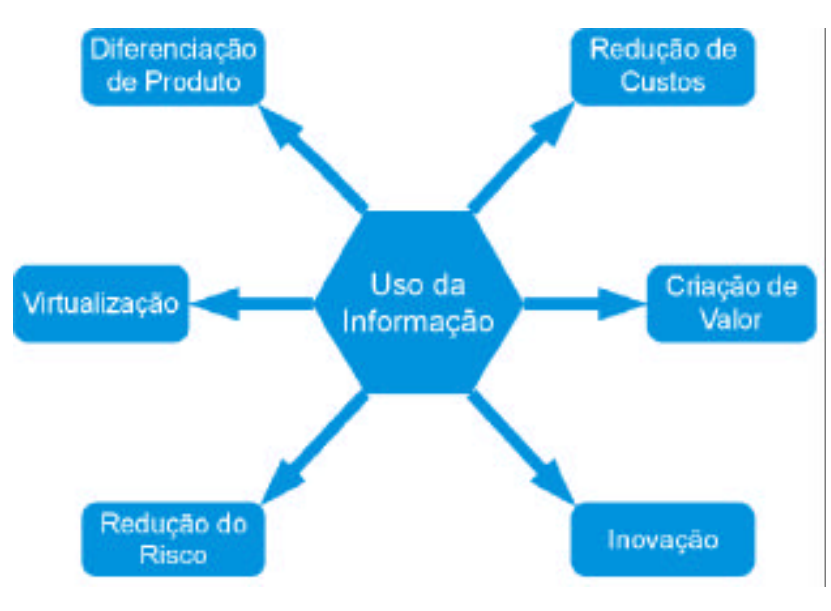

$\mathrm{N}$ este momento tem-se o início do processo de construção da teoria, que consistiu em abstração, generalização, relacionamento, seleção, síntese e ideal ização ${ }^{62,63,64}$. C abe, a partir de agora, servindo como indicativo para futuros trabalhos, a construção do instrumento de medida para cada uma das dimensões propostas, com o objetivo de validar os constructos citados e a confirmação teórica propriamentedita. 


\section{A Iguns aspectos do uso da informação na economia da informação}

A quantificação do uso da informação, na estrutura aqui proposta, permitiráo estabelecimento deum grau dentro de uma escala apropriada. Com isso, será possível discriminar pontualmente as posições das organizações no modelo. Lembra-sequea medida, umavez criada, não éo fim, mas um meio dentro do processo de descrição, diferenciação, explanação, predição, diagnóstico ou tomada de decisão ${ }^{65}$.

A rtigo aceito para publicação em 18-11-2002

\section{REFERÊNCIAS}

1. SHAPIRO, Carl; VARIAN, H al R. A economia da informação: como os princípios econômicos se aplicam a era da I nternet. Rio de Janeiro : C ampus, 1999.

2. EVAN S, Philip B.; WU RSTER, Thomas S. A explosão dos bits: blown to bits. Rio de J aneiro : C ampus, 2000.

3. SHAN NON, Claude E.; WEA VER, Warren. The mathematical theory of communication. U rbana: The U niversity of I Ilinois, 1949.

4. WESTPHAL, Christopher \& BLAXTON, Teresa. D ata mining solutions: methods and tools for solving realworld problems. $\mathrm{N}$ ew York : John Wiley, 1998.

5. CO ELH O N ETTO, J. T eixeira. Semiótica, informação ecomunicação: diagrama da teoria do signo. [S. I.] : Perspectiva, 1980.

6. SIMON, H erbert A. Administrative behavior: astudy of decisionmaking processes in administrative organizations. 4. ed. $\mathrm{N}$ ew York : F ree Press, 1997

7. A LTER, Steven. I nformation systems: a management perspective. M enlo Park : Benjamin/C ummings, 1996.

8. CHECKLAN D, Peter; H O LWELL, Sue. I nformation, systemsand information systems: making sense of the field. C hichester : John Wiley, 1998.

9. LAUDON, Kenneth C . ; LA U D O N, JaneP. M anagement information systems: new approaches to organization and technology. 5. ed. U pper Saddle River : Prentice H all, 1998.

10. ZWA SS, Vladimir. Management information systems. D ubuque Wm. C. Brown, 1992

11. SIEGFRIED, Tom. 0 bit e o pêndulo: a nova física da informação. Rio de Janeiro : C ampus, 2000.

12. DA AEN PORT, Thomas H . E cologia da informação: por que só a tecnologia não basta para o sucesso na era da informação. São Paulo : Futura, 1998.

13. DRU CKER, Peter F . A organização fundamentada na informação. In: D RU CKER, Peter F. ( 0 rg.). A snovas realidades: no governo e na política, na economia e nas empresas, na sociedade e na visão do mundo. 3. ed. São Paulo : Pioneira, 1993. p. 177-188.

14. PORTER, Michael E. ; MILLAR, Victor E. H ow information gives you competitive advantage. $\mathrm{H}$ arvard Business R eview, J ul./ A go.1985.

15. A LBERTIN , A lberto Luiz. Administração deinformática: funçõese fatores críticos de sucesso. 3. ed. São Paulo : A tlas, 2001.

16. $\mathrm{NO} O \mathrm{LAN}$, Richard $\mathrm{L}$. M anaging the crises in data processing. $\mathrm{H}$ arvard Business Review, v. 57. n. 2. p.115-126, M ar./A pr. 1979.
17. MEIRELLES, Fernando de Souza. Informática: novas aplicações em microcomputadores. 2. ed. São Paulo : Makron Books, 1994.

18. BIN DER, Marcelo:; COHEN, Max. N ew perspectives in the Brazilian flight sector: the entrance of $\mathrm{G}$ ol Linhas A éreas. In: B usiness Association of $L$ atin A merica. T ampa, Florida, 2002.

19. HOWELL, Bob. U sing information for strategic cost reduction. In: MARCH AN D, D onald A .(O rg.).C ompeting with information: a manager's guide to creating business value with information content. C hinchester, England : Wiley, 2001. p.165-191.

20. FIN E, C harles H . M ercados em evolução contínua: conquistando vantagem competitiva num mundo em constante mutação. Rio de Janeiro : C ampus, 1999.

21. WO O , York Y. ; H SU, Shu-Lu. O rder processing cost reduction in a joint vendor-buyer inventory system via the application of information technology. The engineering economist, v. 45, n. 4, p.350-365, 2000.

22. RO SEN BERG, Barry; MECH AM , M ichael. M RO softwarepuzzle: airlines pick and choose. Aviation Week \& Space Technology, Mar. 2001.

23. PORTER, M ichael E. C ompetitive advantage N ew York : Free Press, 1985.

24. RAM IREZ, Rafael. Value co-production: intellectual origins and implications for practice and research. Strategic M anagement J ournal. v. 20, p. 49-65, 1999.

25. STABELL, Charles B. ; FJELDSTAD, $\varnothing$ ystein D. C onfiguring value for competitive advantage: on chains, shops, and networks. Strategi c M anagement J ournal, v. 19, p. 413-437, 1998.

26. BO WMAN, Cliff. Value in the resource-based view of the firm: a contribution to the debate. The A cademy of $M$ anagement $R$ eview, v. 26. n. 4. p. 501-502, 0 ct., 2001.

27. BOWMAN , Cliff; AMBRO SINI, Veronique. Value creation versus value capture: towards a coherent definition of value in strategy. B ritish J ournal of M anagement, v. 11, n. 1. p. 1-15, Mar. 2000.

28. VEN KATRAMAN, N . I. Enable business transformation: from automation to business scope redefinition. Sloan M anagement Review, p. 73-87, Winter 1994.

29. MARCHAN D, D onald A ; KETTIN GER, William J .; RO LLIN S, John D. Information orientation: people, technology and the bottom line. Sloam M anagement R eview, p. 69-80, Summer 2000.

30. SA WH N EY, M ohanbir. D on't homogenize, synchronize. $\mathrm{H}$ arvard BusinessReview, p.101-108, Jul./A go. 2001.

31. KA LAKO TA, Ravi; RO BIN SO N , M arcia. E-business: estratégias para alcançar o sucesso no mundo digital. 2. ed. Porto A legre : Bookman, 2002.

32. LITAN, Robert E.; RIVLIN , A lice M. Projecting the economic impact of the Internet. TheA merican E conomic R eview, v. 91, n. 2 p. 313-317, M ay 2001.

33. H O RO VITZ, Jacques. U sing information to bond with customers. In: M ARC H AN D, D onald A. (O rg.). Competing with information: a manager's guide to creating business value with information content. Chinchester, England : Wiley, 2001. p. 35-53.

34. D H A R, Vasant; STEIN , Roger. I ntelligent decision support methods: the science of knowledge work. U pper Saddle River : Prentice$\mathrm{H}$ all, 1997. 


\section{Max F. Cohen}

35. TURBAN, Efraim; ARO N SO N, J ay E. D ecision support systems and intelligent systems. U pper Saddle River : Prentice-H all, 1998.

36. COYNE, Kevin P.; DYE, Renée. The competitive dynamics of network-based business. H arvard B usiness R eview. p. 99-109, J an./ Feb. 1998.

37. SAWH NEY, M ohanbir; PARIKH, D eval. Where value lives in a networked world. H arvard Business R eview, p. 79-86, J an. 2001.

38. PO RTER, M ichael E. What is strategy? $H$ arvard B usiness R eview, p. 61-79, N ov./D ec.1996.

39. N O GU EIRA, Roberto; SO A RES, C íntia. U tilização estratégica da Internet: um estudo nos bancos operando no Brasil. In: ENCONTRO DA ASSOCIAÇÃO NACIONAL DOS PROGRAMAS DE PÓS-GRADUAC ÃO EM AD MIN ISTRAÇÃO. Anais... C ampinas : [s.n.], 2001. 1 CD ROM.

40. EPPIN GER, Steven D. Innovation at the speed of information. $H$ arvard B usiness R eview, p. 149-158, J an. 2001.

41. TH O M KE, Stefan; H IPPEL, Eric von. C ustomers as innovators: a new way to create value. $H$ arvard Business R eview, p. 74-81, A pr. 2002.

42. A M O R, D aniel. A ( r) evolução do e-business. São Paulo : M akron Books, 2000

43. DE GEU S, A rie P. Planning as learning. $H$ arvard B usiness $R$ eview. p. 70-74, Mar./A pr. 1988.

44. GO MES, Elisabeth; BRA G A, F abiane. Inteligência competitiva: como transformar informação em um negócio lucrativo. Rio de Janeiro : C ampus, 2001.

45. DESCH A M PS, J ean-Philippe. From information and knowledge to innovation. In: M ARCH AN D, D onald A . ( 0 rg.). Competing with information: a manager's guide to creating business value with information content. C hinchester/England: Wiley, 2001. p.127-145.

46. CRU Z, T adeu. G erência do conhecimento. São Paulo : C obra, 2002.

47. LEMOS, Cristina. Inovação na era do conhecimento. In: LA ST RES, H elena M . M ;. A LBA G LI, Sarita . (O rg.). I nformação e globalização na era do conhecimento. Rio de Janeiro : C ampus, 1999. p. 122-144.

48. H AMILTO N, Stewart. I nformation and the management of risk. In: M A RCH A N D , D onald A. (O rg.). C ompeting with information: a manager's guideto creating business valuewith information content. C hinchester/England: Wiley, 2001. p. 195-207.

49. BAN C O CEN TRAL D O BRA SI L. O novo sistema depagamentos brasileiro. Disponível em: < http://www.bcb.gov.br/htms/spb/ ospbevoce/ EntendaoSPB/home.htm> . A cesso em: 22 abr. 2002
50. HAMILTON, Stewart. Controlling risks. In: MARCHAND, $D$ onald $A$. ( $O$ rg.). C ompeting with information: a manager's guide to creating business value with information content. C hinchester/ England: Wiley, 2001. p. 209-228.

51. CA M PO S, Renato de; SA N TO S, L uciana Rocha dos. M odelagem de processos e definição de requisitos para sistemas de informações para a previsão de demanda. I n: EN C O NTRO D A ASSO CI AÇ ÃO N ACIO N AL D O SPRO GRAMASDE PÓ S-G RADU AÇÃO EM AD M IN IST RAÇÃO , 25., 2001, C ampinas. Anais ... Campinas, 2001. 1 CD -ROM

52. RO CKART, John $F$. C hief excutives define their own data needs. H arvard B usiness R eview, p. 81-93, M ar./A pr. 1979.

53. ANGEHRN, A lbert A. Designing mature Internet business strategies: the ICDT model. European M anagement J ournal, v. 15, n. 4. A ug. 1997.

54. D A VIS, Stan; M EYER, C hristopher. Blur : the speed of change in the connected economy. [S. I.] : Little Brown, 1999.

55. A LBERTIN , A lberto Luiz. C omércio eletrônico: modelo, aspectose contribuições de sua aplicação. 3. ed. São Paulo : A tlas, 2001.

56. RAYPORT, Jeffrey F.; SVIOKLA, John J. Managing in the marketspace. H arvard B usiness R eview, p. 141-150, N ov./ D ec. 1994.

$57 . \quad$ Exploiting the virtual value chain. $\mathrm{H}$ arvard $\mathrm{B}$ usiness Review, p. 75-85, N ov./D ec. 1995.

58. VEN KATRAMAN, N .; HEN DERSO N, J ohn C. Real strategies for virtual organizing. Sloan M anagement Review, p. 33-48, 0 ct. 1998.

59. GARTN ER GRO U P. Virtual Enterprise Scenario. In: GARTNER CONFEREN CE, 1999.

60. MEIRELLES, Fernando de Souza. Fundação Getulio Vargas Escola de Administração de Empresas de São Paulo. In: PESQ UISA AN U AL DE TECN O LO GIA DE IN FORMAÇÃO, 13., 2000. São Paulo : [s. n.], 2002.

61. TA PSC O TT, D on; LO WY, A lex; TIC O LL, D avid. Plano de ação para uma economia digital. São Paulo : M akron Books, 2000.

62. WEICK, Karl E. What theory is not, theorizing is. Administrative ScienceQ uartely, v. 40, p. 385-390, Sept. 1995.

$63 . \quad$ Theory construction as disciplined imagination. Academy of M anagement Review, v. 14, n. 5, p. 516-531, 1989.

64. SUTTON, Robert I.; STAW, Barry M. What theory is not. AdministrativeScience Q uartely, v. 40, p. 371-384, Sept. 1995.

65. PEDHAZUR, Elazar J.; SCHMELKIN, Liora Pedhazur. M easurement, design and analysis: an integrated approach. $\mathrm{H}$ illsdale : Lawrence Erlbaum, 1991. 